
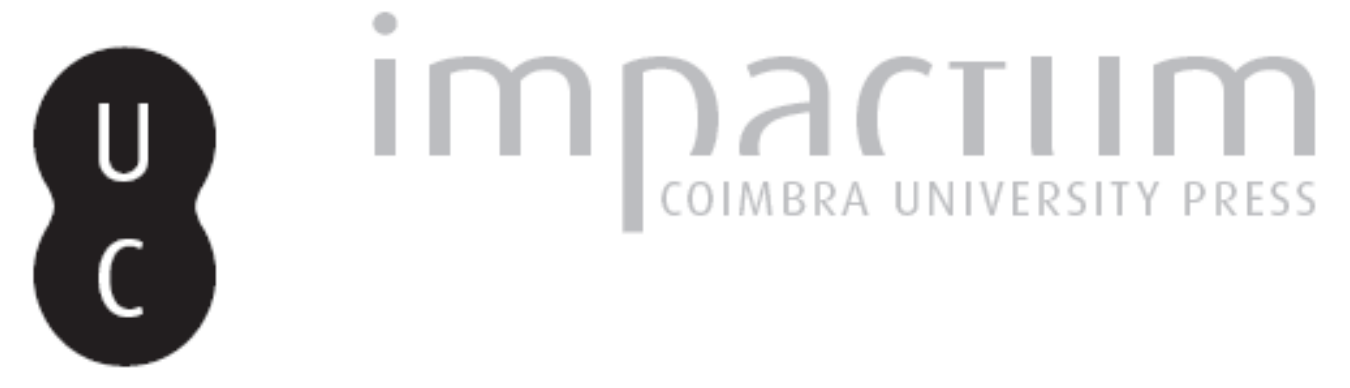

Fortuna e ressentimento: o incrível caso dos Abreu Guimarães (c.1740-1807)

Autor(es): $\quad$ Franco, Renato

Publicado por: Imprensa da Universidade de Coimbra

URL persistente: URI:http://hdl.handle.net/10316.2/40687

DOI: $\quad$ DOI:https://doi.org/10.14195/0870-4147_47_12

Accessed : $\quad$ 26-Apr-2023 10:41:11

A navegação consulta e descarregamento dos títulos inseridos nas Bibliotecas Digitais UC Digitalis, UC Pombalina e UC Impactum, pressupõem a aceitação plena e sem reservas dos Termos e Condições de Uso destas Bibliotecas Digitais, disponíveis em https://digitalis.uc.pt/pt-pt/termos.

Conforme exposto nos referidos Termos e Condições de Uso, o descarregamento de títulos de acesso restrito requer uma licença válida de autorização devendo o utilizador aceder ao(s) documento(s) a partir de um endereço de IP da instituição detentora da supramencionada licença.

Ao utilizador é apenas permitido o descarregamento para uso pessoal, pelo que o emprego do(s) título(s) descarregado(s) para outro fim, designadamente comercial, carece de autorização do respetivo autor ou editor da obra.

Na medida em que todas as obras da UC Digitalis se encontram protegidas pelo Código do Direito de Autor e Direitos Conexos e demais legislação aplicável, toda a cópia, parcial ou total, deste documento, nos casos em que é legalmente admitida, deverá conter ou fazer-se acompanhar por este aviso. 


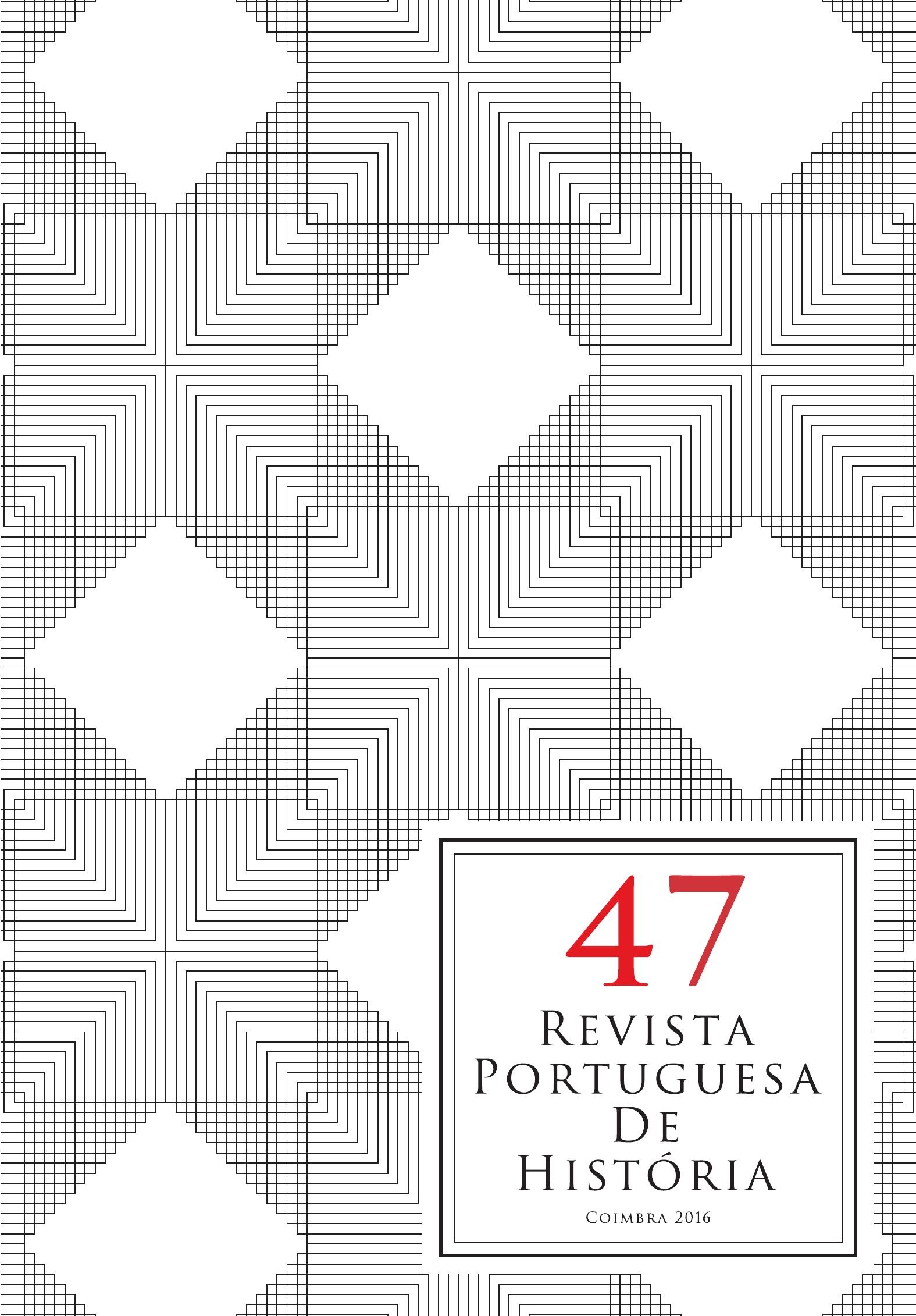




\title{
Fortuna e ressentimento: o incrível caso dos Abreu Guimarães (c.1740-1807)
}

\section{Fortune and resentment: the incredible case of Abreu Guimarães (c.1740-1807)}

\author{
Renato Franco ${ }^{1}$ \\ Universidade Federal Fluminense \\ renfranco@gmail.com
}

Texto recebido em/Text submitted on: 31/01/2016

Texto aprovado em/Text approved on: 22/06/2016

\section{Resumo:}

Este artigo analisa a trajetória do negociante Antônio de Abreu Guimarães, português nascido na região do Minho, de origem humilde, e que se tornaria dono de um dos maiores cabedais da capitania de Minas Gerais, na segunda metade do século XVIII. Auxiliado pelo sobrinho, Francisco de Abreu Guimarães, amealhou grande quantidade de bens diversos, terras e escravos, somando uma fortuna considerável e, em 1787, daria origem ao chamado "Vínculo da Jaguara", que doravante se tornava posse inalienável destinada ao financiamento de obras pias, como a criação de hospitais, seminário, recolhimento de órfãs. No entanto, antes mesmo de se efetivar, o dito Vínculo provocou uma série de desentendimentos familiares que foram fundamentais para compreender a dinâmica e o fracasso das pretensões originais do negociante.

\section{Palavras-chave:}

Vínculo da Jaguara; Negociantes; História da assistência.

\section{Abstract:}

This article analyzes the history of the merchant Antônio de Abreu Guimarães, a Portuguese from a poor family in the Minho region who becomes one of the wealthiest men of the captaincy of Minas Gerais in the second half of the 18th century. Helped by his nephew Francisco de Abreu Guimarães, he amassed large quantities of various goods, land and slaves, building up a considerable fortune and, in 1787 , giving rise to so-called "Vínculo da Jaguara", which henceforth became inalienable possession for financing charity work, such as the creation of hospitals, seminary, carring for orphaned children. However, before becoming effective, it triggered a series of family disagreements that were fundamental to understand the dynamics and the failure of the original merchant's intent.

Keywords:

Vínculo da Jaguara; Merchants; History of poor relief.

${ }^{1} \mathrm{O}$ autor agradece leitura e as sugestões do prof. dr. Ângelo Alves Carrara; agradece ainda a bolsista de Iniciação Científica Bianca Racca que auxiliou na transcrição de parte das fontes. 


\section{Talento e riqueza}

Antônio de Abreu Guimarães nasceu na freguesia de São Vicente de Mascotelos, termo da vila de Guimarães, arcebispado de Braga, nos idos de 1710. Era cristão-velho e filho legítimo de Domingos Fernandes e Ângela Abreu, lavradores "em terras suas e alheias", onde também tinham uma venda de vinhos em que comerciavam "vinhos seus e alheios"; os avós paternos eram Jerônimo Fernandes e Ana Azevedo, e os maternos eram João Antunes, ferreiro, e Maria de Abreu, mulher de "segunda condição".

Como muitos outros de seu lugar de origem, ainda jovem migrou para a América. Desde o início da colonização, da região norte de Portugal saíram grandes contingentes populacionais que rumavam para o ultramar em busca de melhores condições de vida; esses fluxos migratórios eram marcadamente masculinos e, a partir do século XVIII, teriam a região aurífera como alvo preferencial ${ }^{3}$. Chegando ao Rio de Janeiro, Antônio começou a trabalhar com "enxada e foice" e, logo em seguida, decidiu vender suas roças e comboiar africanos para as Minas. Ali permaneceu comerciando, a cavalo, "gêneros de roça" até conseguir montar sua própria "loja de mercadorias de diversos gêneros" na qual vendia os produtos pessoalmente. Nessa época, era comum Antônio de Abreu Guimarães fazer o trajeto entre Rio e Minas para abastecer seu pequeno negócio, no arraial do Carijós, um povoado que ficava no "Caminho

${ }^{2}$ Informações retiradas de Instituto Arquivos Nacionais/Torre do Tombo, Lisboa (ANTT), Registo Geral de Mercês de D. José I, liv. 18, f. 240.

${ }^{3}$ Joel Serrão, "Conspecto histórico da emigração portuguesa", Análise Social, vol. 8, n. 32 (1970), p. 597-617. Donald Ramos, "From Minho to Minas: The Portuguese Roots of the Mineiro Family", The Hispanic American Historical Review, v. 73, n. 4 (Nov., 1993), p. 639-662. Recentemente o artigo foi traduzido para o português: "Do Minho a Minas", Revista do Arquivo Público Mineiro, v. 44 (2008), p.132-153. Caroline Brettell, Homens que partem, mulheres que esperam - consequências da emigração numa vila minhota, Lisboa, Dom Quixote, 1991. Jorge Pedreira. "Brasil, fronteira de Portugal. Negócio, emigração e mobilidade social (séculos XVII e XVIII)", Revista Anais da Universidade de Évora, n. 8-9, (1998-1999). p. 69-72. Robert Rowland, Brasileiros do Minho: Emigração, propriedade e família in: Francisco Bethencourt \& Kirti Chaudhuri (Orgs.), História da expansão portuguesa: do Brasil para África (1808-1930), Lisboa, Círculo dos Leitores, 1998, vol. 4, p. 324-347. A. J. R. Russell-Wood, “A emigração: fluxos e destinos" in: Francisco Bethencourt \& Kirti Chaudhuri (Orgs.), História da expansão portuguesa: o Brasil na balança do império (1697-1808), Lisboa, Círculo dos Leitores, 1998, vol. 3, p. 158-68. Jorge Fernandes Alves, "Variações sobre o "brasileiro" - Tensões na emigração e no retorno do Brasil", Revista Portuguesa de História, Universidade de Coimbra, tomo 33, (1999), p.191-222. 
Novo", pelo qual se chegava a Itaverava, Guarapiranga, Mariana e Catas Altas. Tempos depois, abriu outra loja no Serro Frio ${ }^{4}$.

Seguindo sua trajetória de ascendência, em 1749, recebeu a patente de capitão de ordenança, em 1753 fora habilitado para Familiar do Santo Ofício. Em 1754, abriu uma casa de negócio em Lisboa e, em 1760, mais uma no Rio de Janeiro ${ }^{5}$. Naquela altura, já era um homem de considerável fortuna, dono de 10 ações originais na Companhia do Grão-Pará e Maranhão, que somavam quatro contos de réis, o que lhe possibilitou - com base no alvará pombalino de 1757 que diferenciou o estatuto social entre mercadores e homens de negócio - reivindicar e conseguir, em 1764, o hábito da Ordem de Cristo, não obstante os defeitos mecânicos que maculavam sua ascendência e ele próprio ${ }^{6}$. Em 1767, foi para Lisboa, mas continuou a governar sua fortuna com o auxílio de seus familiares. Quando faleceu, em 1801, era, segundo ele próprio, um dos maiores cabedais de Minas Gerais, com negócios que se estendiam por Pernambuco, Rio de Janeiro, Minas Gerais e Portugal. O testamenteiro teria quatro anos para findar seu inventário?

Guardadas as especificidades, essa história não era exatamente uma excepcionalidade para muitos portugueses que atravessavam o Atlântico a fim de conseguir riqueza em espaços abertos ao talento e à indústria. As redes estabelecidas em várias partes do império - e também fora dele - mostram o incontornável papel do comércio na formação de fortunas, beneficiando agentes

${ }^{4}$ Informações retiradas de Instituto Arquivos Nacionais/Torre do Tombo, Lisboa (ANTT), Registo Geral de Mercês de D. José I, liv. 18, f. 240 e ANTT, Tribunal do Santo Ofício, mç. 118, doc. 2027

${ }^{5}$ ANTT, "Memória do que tenho praticado com meu sobrinho António de Abreu Martins e seu irmão o coronel Francisco de Abreu Guimarães e com António Ribeiro de Faria e eles comigo", Hospício da Terra Santa, mç 38, cx. 20. fl.10.

${ }^{6}$ ANTT, Registo Geral de Mercês de D. José I, liv. 18, fl. 240. Ver: Jorge Miguel Pedreira, "Os Negociantes de Lisboa na Segunda Metade do Século XVIII: Padrões de Recrutamento e Percursos Sociais”, Análise Social, 116-117 (quarta série, vol. XXVII), 1992 (2. ․-3. ), p. 407-440.

${ }^{7}$ Para a patente de capitão, ver: ANTT, Registro Geral de Mercês de Dom João V, Livro 40, fl. 324; para habilitação, ver: ANTT, Tribunal do Santo Ofício, mç. 118, doc. 2027; Tribunal do Santo Ofício, Antônio, mç, 162, doc. 2529. Ver ainda: Aldair Carlos Rodrigues, "Viver à lei da nobreza: familiaturas do Santo Ofício, Ordens Terceiras, câmaras e Ordem de Cristo num contexto de mobilidade social (Minas Gerais, século XVIII)", Congresso Internacional Pequena Nobreza nos Impérios Ibéricos de Antigo Regime, (2011), (http://www.iict.pt/pequenanobreza/ arquivo/Doc/res004-pt.pdf), p. 13-14. Para o testamento de Antônio de Abreu Guimarães, ver: ANTT, Feitos Findos, Registo Geral de Testamentos, Livro 349, fls. 68-76. Agradeço a Danielle Sanches de Almeida que gentilmente localizou este testamento. 
em diferentes lugares ${ }^{8}$. Não foi possível saber se Antônio era o primeiro de sua família a ir para a América, mas seguramente não foi o último; ao longo de sua vida, ajudou parentes, inserindo-os em suas redes pessoais". Não bastasse a incrível história de um português nascido pobre que se tornou dono de um expressivo espólio, Antônio de Abreu Guimarães destinou para obras de caridade uma quantia invulgar por meio de uma vinculação de bens, autorizada por decreto régio, em 1787.

Este artigo trata das histórias e conflitos pessoais em torno de um conjunto expressivo de terras que somava 1.300 alqueires ${ }^{10}$ de áreas de pastagens, lavouras e mineração, na região de Sabará, comarca do Rio das Velhas, capitania de Minas Gerais. Por meio das duas trajetórias é possível iluminar estratégias de enriquecimento e administração das fortunas daqueles que migravam do Minho para a região das Minas.

\section{O "labirinto" de Francisco de Abreu Guimarães}

Francisco de Abreu Guimarães nasceu na freguesia de São Vicente de Mascotelos, termo da vila de Guimarães, arcebispado de Braga, em 11 de setembro de 1732. Era cristão-velho e filho legítimo de Manuel Martins e Dominga Francisca de Abreu, irmã, por parte do pai, de Antônio de Abreu Guimarães ${ }^{11}$. Os avós paternos eram "lavradores de seus próprios bens, que cultivam por si e seus criados", "ricos de bens de raiz e dinheiros"; seus avós

\footnotetext{
${ }^{8}$ Ver: João Fragoso, Homens de grossa aventura - acumulação e hierarquia na praça mercantil do Rio de Janeiro, 1790-1830, Rio de Janeiro, Civilização Brasileira, 1998. Jorge Pedreira. "Brasil, fronteira de Portugal. Negócio, emigração e mobilidade social (séculos XVII e XVIII)”, Revista Anais da Universidade de Évora, n. 8-9, (1998-1999). Cláudia Maria das Graças Chaves, Perfeitos Negociantes: Mercadores das Minas Setecentistas, São Paulo, Annablume, 1999. Júnia Ferreira Furtado, Homens de negócio - a interiorização da metrópole e do comércio nas Minas setecentistas, São Paulo, Hucitec, 1999.

${ }^{9}$ Jorge Pedreira observou o importante papel de acolhimento baseado em redes familiares ou de compadrio e sua relevância para a conformação de uma carreira comercial, padrão que se estenderia, inclusive, ao período pós-independência do Brasil. Jorge Pedreira. "Brasil, fronteira de Portugal...", cit., p. 69-72.

10 "Sucinta descrição da fazenda do Jaguara no estado de Minas Gerais", Revista do Arquivo Público Mineiro, v. 11, 1907, p. 585-597.

${ }^{11}$ Arquivo Histórico Ultramarino, Lisboa (AHU), Minas Gerais, "Requerimento de Francisco de Abreu Guimarães, morador na vila do Sabará, solicitando ao rei a mercê de o recompensar pelos serviços prestados na Real Casa de Fundição da referida vila”, cx. 96, doc. 31.
} 
maternos eram "lavradores de seus próprios bens, que cultivavam por si e seus criados, sem terem outro ofício ou exercício mecânico"12.

Francisco saiu de casa com cerca de 12 anos de idade para "aprender negócio" na América, seguramente pelas mãos do tio ${ }^{13}$. Na década de 1750, Antônio não fazia apenas o trajeto entre Rio e Minas, mas atravessava frequentemente o Atlântico para negociar produtos em Portugal e revendê-los no Brasil. Em virtude do volume de comércio e dos longos períodos de ausência, tanto em Minas quanto em Lisboa, a presença de familiares era providencial, por isso, Francisco desempenharia um papel fundamental: ficou encarregado de cuidar dos negócios baseados em Sabará, comarca do Rio das Velhas, Minas Gerais ${ }^{14}$.

Em janeiro de 1754, Antônio de Abreu Guimarães saiu do Rio de Janeiro rumo a Lisboa e só regressaria à América em 1760, permanecendo até 1767, quando novamente viajou para Lisboa para nunca mais voltar ao Brasil. Enquanto isso, os negócios em Minas iam de vento em popa, com investimentos em comércio e extração de ouro, na contramão de um período de queda na produção mineral ${ }^{15}$. De partida para Portugal, Antônio incumbiu seu sobrinho Francisco para administrar a recém-comprada fazenda da Jaguara. Naquele ano de 1767, nem Francisco nem Antônio sabiam que nunca mais se veriam pessoalmente, embora a volta do tio para encabeçar os negócios em Minas e ida do sobrinho para Portugal estivessem previstas ${ }^{16}$.

${ }^{12}$ ANTT, Tribunal do Santo Oficio, Conselho Geral, Habilitações, Francisco, mç. 101, doc. 1629

${ }^{13}$ Robert Rowland ressaltou o caráter quase exclusivamente masculino da emigração do Entre Douro e Minho, em que o papel dos tios era fundamental para a decisão de emigrar. Ver: Robert Rowland, "Velhos e novos Brasis" in Francisco Bethencourt \& Kirti Chaudhuri (Orgs.), História da expansão portuguesa: do Brasil para África (1808-1930), Lisboa, Círculo dos Leitores, 1998, vol. 4, p. 303-373. Para um estudo de caso sobre a emigração para Ásia, ver: Isabel dos Guimarães Sá, "As misericórdias e as transferências de bens: o caso dos Monteiros, entre o Porto e a Ásia (1580-1640)”, Tempo (Niterói, online), vol. 22, n. 39, (2016) (http://www.historia.uff.br/tempo/ site/wp-content/uploads/2016/04/05-Isabel-dos-Guimaraes-port.pdf), p. 88-109.

${ }^{14}$ Para uma reflexão global sobre os diferentes aspectos dos movimentos populacionais dos portugueses durante a época moderna ver: A. J. R. Russell-Wood, "Flux and reflux of people" in The portuguese empire, 1415-1808-a world on move, London, John Hopkins, 1998, p. 58-122.

${ }^{15}$ Para a temporalidade das extrações minerais ver: Virgílio Noya Pinto, O ouro brasileiro e o comércio anglo-português, São Paulo, Cia Nacional, 1979. Rita Martins de Sousa, "Brazilian Gold and the Lisbon Mint House (1720-1807)", Electronic Journal of Portuguese History, vol. 6, number 1, 2008. (http://www.brown.edu/Departments/Portuguese_Brazilian_Studies/ejph/ $\mathrm{html} /$ issue $11 / \mathrm{pdf} /$ rsousa.pdf)

${ }^{16}$ Informações extraídas da petição de Francisco de Abreu Guimarães, AHU, Minas Gerais, "Consulta do Conselho Ultramarino sobre os requerimentos de Antônio de Abreu Guimarães e de seu sobrinho, o coronel Francisco de Abreu Guimarães, nos quais um pede providências para a execução dos estabelecimentos pios na capitania de Minas Gerais e o segundo pede a suspensão da dita fundação até haver separação de bens" (vários documentos), cx. 152, doc. 56. (doc. 2). 


\section{Ouro, terras e desentendimentos}

Quando Francisco aceitou o encargo de cuidar da fazenda, a Jaguara era um exemplo de prosperidade: entre agosto de 1767 e agosto de 1768, declarara mais de nove arrobas - isto é, $132,21 \mathrm{~kg}$ - de ouro na casa de fundição de Sabará, pagando por isso mais de uma arroba referente ao quinto ${ }^{17}$. Em carta escrita em novembro de $1769^{18}$, avisou o tio de que estavam principiando uma lavra, cuja previsão era extrair em torno de uma arroba. No fim de 1770, haviam sido apuradas 1.200 oitavas e no terreno da fazenda foram descobertas áreas de cupiaras, ou seja, ouro de superfície localizado nos cascalhos das beiras dos rios, onde os negros faiscavam "domingos e dias santos, até de noite pela lua".

Por orientação do tio, Francisco iniciou uma estratégia que jamais abandonaria: comprar terras, investindo substanciais somas de dinheiro. As riquezas e os gastos feitos na Jaguara eram diversificados, com expectativas de ganhos minerais, mas apostando também na criação de gado, tudo isso, acompanhado da compra de escravos, e também arrendando parte da exploração mineral a meeiros. Em 1771, Francisco arrematou um sítio com 200 cabeças de gado, a seis mil cruzados à vista, com "terras e pastos de criar" e "alguns matos para plantas"; na mesma época, promovia a derrubada nos matos de outra área, para fazer "uma grande fazenda", com sítio, paiol e aguadas. Dois meses mais tarde, no mesmo ano de 1771, reiterava sua intenção de comprar terras vizinhas que somavam 12 mil cruzados ${ }^{19}$. Desde o princípio, a exploração da região das Minas favorecera o investimento paralelo em agricultura e pecuária destinadas a atender à crescente demanda por gêneros de subsistência, contudo, especialmente a partir do último terço do século XVIII, a exaustão dos veios significou o esgotamento econômico das áreas minerais, comprometendo os demais setores ${ }^{20}$.

${ }^{17}$ AHU, Minas Gerais, "Requerimento de Francisco de Abreu Guimarães, morador na vila do Sabará, solicitando ao rei a mercê...”, cit., cx. 96, doc. 31 .

${ }^{18} \mathrm{Na}$ documentação pesquisada há um conjunto de cartas de Francisco, enviadas ao tio entre 1769 e 1797. Infelizmente, não foram localizadas as respostas de Antônio.

19 "Não tenho perdido ocasião das compras que Vossa Mercê me recomenda" Carta de 20/06/1771. Para as demais informações acima, ver cartas de 06/11/1769, 13/12/1770, 14/04/1771. AHU, Minas Gerais, "Consulta do Conselho Ultramarino sobre os requerimentos de Antônio de Abreu Guimarães e de seu sobrinho...", cit., cx. 152, doc. 56.

${ }^{20}$ Ângelo Alves Carrara, “A capitania de Minas Gerais (1674-1835): modelo de interpretação de uma sociedade agrária”, História Econômica \& História de Empresas, v. 3, n.2, (2001), p. 47-63. Do mesmo autor, ver ainda: Agricultura e pecuária na capitania de Minas Gerais; 1674-1807. Doutorado em História, UFRJ, 1997. 
Francisco gostaria de ter regressado a Lisboa, mas seguiu administrando os negócios em Minas; em 1772, o tio cedeu aos pedidos do sobrinho autorizando-o a regressar a Portugal, mas por fim Francisco deu por bem permanecer na América. Na resposta ao tio, valorizou o caráter de renúncia e o amor filial que o fizeram continuar nas Minas e, segundo ele próprio, de livre vontade, "por dinheiro nenhum" se sujeitaria "às pensões e encargos" que aturava. Aproveitando o tom amigável da missiva, contou que circulava um boato por Sabará de que Antônio havia morrido em Portugal. Por isso, aconselhou-lhe a fazer um inventário de tudo ${ }^{21}$.

Apesar de cartas amistosas, não tardou para que os desentendimentos surgissem e o tio reclamasse notícias. Em janeiro de 1773, Francisco discordou da grande quantidade de demandas desnecessárias, trabalhosas, e consideradas fáceis apenas porque o tio não tinha a real dimensão do que era executá-las. À medida que as cartas rareavam em frequência, tornaram-se mais ásperas: "No primeiro capítulo me põe Vossa Mercê de omisso (...); concedo que assim seja, por eu não ser Santo Antônio para residir em toda a parte, e ser dificultosa empresa achar pessoa com as circunstâncias necessárias para suprir a minha ausência" ${ }^{2}$. Não é possível saber se Francisco controlava sozinho todos os processos que envolviam os bens do tio em Minas, mas não era raro que reclamasse dos "labirintos" de trabalho em que sempre se encontrava, oprimido pelo volume de afazeres e pelo aumento contínuo das terras.

Além da grande dificuldade em conseguir mão de obra qualificada, alegava que as possessões não rendiam como o previsto. Em meados da década de 1770, as relações azedaram-se, com Francisco arrematando em tom desafiador, em novembro de 1776: "o ruim administrador se não deve conservar na administração, depois que se conhece, nem mais um instante, razão por que

21 "Diz-me Vossa Mercê que sendo eu ainda esteja desejoso de ir para essa terra e me seja penosa a demora que Vossa Mercê ainda poderá ter, que o faça ainda que se perca o que se perder". Carta de 14/07/1772. Ver ainda doc. 2 e carta de 14/07/1772 em AHU, Minas Gerais, "Consulta do Conselho Ultramarino sobre os requerimentos de Antônio de Abreu Guimarães e de seu sobrinho...", cit., cx. 152, doc. 56.

22 "Na primeira me inteira Vossa Mercê e faz certo as circunstâncias e vantagens da Fazenda da Jaguara, as quais eu não desconheço, porém não aprovo, olhando para o pouco que Deus nos poderá dar de vida e que este se podia passar sem tais labirintos, que suposto ao que Vossa Mercê lhe parece segundo o que na sua me diz ser muito fácil o contexto dela é pelo não ter experimentado" Carta de 30/01/1773; Carta de 04/04/1774. AHU, Minas Gerais, "Consulta do Conselho Ultramarino sobre os requerimentos de Antônio de Abreu Guimarães e de seu sobrinho...", cit., cx. 152, doc. 56. 
devo dizer a Vossa Mercê que determinou mande quem o faça melhor" ${ }^{23}$. Não é possível saber se Francisco tinha conhecimento dos planos do tio, mas o fato é que em meio a tantas peleias nas correspondências, em julho de 1777, Antônio de Abreu Guimarães enviara uma consulta à rainha, pedindo autorização para vincular todos os seus bens existentes em Minas Gerais, com o intuito de ajudar os pobres "nacionais" da América ${ }^{24}$.

Com base apenas na correspondência, o clima não melhorou até que, em agosto de 1778, Francisco recuou e pediu perdão ao tio, alegando que todos os atrasos se deviam à grande quantidade de trabalho. Esclareceu que o café havia se adaptado bem à terra e, dessa vez, finalizou sua carta amistosamente ${ }^{25}$. Anunciada a trégua, o sobrinho continuou a comprar terras em nome do tio. Nas descrições das novas possessões, as referências ao ouro pareciam acompanhar a tendência geral da capitania e seguiram minguando à medida que avançava o século.

No fim de 1779, Francisco adquiriu um conjunto de terras com 16 escravos, pouco mais de 20 cavalos e cerca de três mil cabeças de gado de leite e de corte. Entre as qualidades da "fazenda do Melo", estava a quantidade de lagoas, lagos, espaços favoráveis à engorda de bois e cavalos, acompanhada do interesse em algumas datas minerais de potencial desconhecido. Apesar das reclamações sobre o decréscimo nos lucros vindos da Jaguara, o novo negócio

${ }^{23}$ Ver cartas de 04/04/1774, 16/02/1775, 22/11/1776 e 02/02/1778. AHU, Minas Gerais, "Consulta do Conselho Ultramarino sobre os requerimentos de Antônio de Abreu Guimarães e de seu sobrinho...", cit., cx. 152, doc. 56.

24 “Senhora, Diz Antônio de Abreu Guimarães, homem de negócio, solteiro, sem ascendentes ou descendentes alguns, natural de vila de Guimarães e por ora assistente nesta Corte, que passando ao Estado do Brasil na sua menoridade, esperançado tão somente na Providência do Altíssimo, adquiriu por meio de sua indústria e negociação o cabedal e fazendas de lavras de ouro, criações e frutos que possui no Rio das Velhas, comarca de Sabará, as quais se acham de presente com mais de 500 escravos e mais de 100 casados e beneficiadas com importantíssimos serviços de grandes levadas de águas reconduzidas de diversas partes muito distantes e dificultosas e continua o suplicante em reconduzir mais de dois rios de importantíssimo custo e com todas as sobreditas águas se pode lavrar e extrair ouro em distância de mais de oito léguas de terras minerais com numerosa escravatura em serviços muito duráveis e sem as ditas águas em nenhum tempo se podia tirar o ouro que tem aquelas terras nas quais já atualmente trabalha muita gente. Produziram copiosos rendimentos administrados com suficiente aplicação, inteligência e zelo. E porque o suplicante no curso de suas negociações e trabalhos fez votos a Deus de aplicar a maior parte dos bens que fosse servido dar-lhe em obras pias do seu maior serviço tendentes à utilidade pública em subsídio das misérias e pobreza dos nacionais daquele continente onde os tinha adquirido" ANTT, Hospício da Terra Santa, mç 38, cx. 20.

${ }^{25}$ Carta de 26/08/1778. AHU, Minas Gerais, "Consulta do Conselho Ultramarino sobre os requerimentos de Antônio de Abreu Guimarães e de seu sobrinho...”, cit., cx. 152, doc. 56. 
custou a bagatela de 20 mil cruzados e foi arrematada da Fazenda Real, por confisco feito ao então falecido coronel João de Souza Lisboa, um dos maiores contratadores de Minas Gerais, e devedor ao Erário Régio. Em maio de 1781, Francisco, impaciente com a enormidade de trabalhos, anunciou mais uma compra na região contígua à Fazenda do Melo, chamada "Barra do Melo", onde, suspeitava-se ter riquezas minerais ${ }^{26}$.

A partir dos documentos, não é possível saber exatamente de onde vinha a grande fortuna que lhe permitira fazer contínuas compras. Francisco, naturalmente, esperava ser recompensado pelos serviços prestados, que iam desde a compra de terras, melhoramento e construção de casas, até a administração de fazendas com escravos, gado, mineração. De diferentes formas, deu a entender que fazia os negócios como se fossem seus, por isso, em 1779, pediu ao tio a aprovação das despesas ${ }^{27}$. Em Minas Gerais, a partir de 1767, todos os negócios foram feitos em uma relação simbiótica em que os dois eram parte interessada.

\section{Ameaças e ingratidão}

Do outro lado do Atlântico, Antônio de Abreu Guimarães envelhecia cada vez mais desconfiado do sobrinho, que parecia demorar demais a dar notícias seguras. Esse mal-estar foi agravado pelos desentendimentos que o tio vinha tendo com Antônio Abreu Martins, irmão de Francisco, que vivia em Lisboa também envolvido em negócios do tio. No fim da vida, Antônio, o tio, redigiu uma ressentida memória em que narrou sua versão da história, alegando ter sido o responsável por levar os dois sobrinhos à América, inserindo-os em suas redes de negócio, apresentando-lhes amigos, tratando-os como filhos, mas os dois sobrinhos, ingratos, estavam associados a outro personagem, Antônio Ribeiro Faria, e todos queriam viver à sua custa. Sem explicar exatamente por que suportar tantos desmandos, Abreu Guimarães narrou os longos anos em que deu boa vida a Ribeiro Faria em sua própria casa em Lisboa ${ }^{28}$.

${ }^{26}$ Carta de 05/05/1781; na carta de 22/11/1779, Francisco deu a dimensão das terras compradas: "A fazenda compõe-se de duas sesmarias de três léguas em quadra cada uma e fica distante da Jaguara sete léguas" AHU, Minas Gerais, cx. 152, doc. 56. AHU, Minas Gerais, "Consulta do Conselho Ultramarino sobre os requerimentos de Antônio de Abreu Guimarães e de seu sobrinho...", cit., cx. 152, doc. 56.

${ }^{27}$ Carta de 21/04/1779. AHU, Minas Gerais, "Consulta do Conselho Ultramarino sobre os requerimentos de Antônio de Abreu Guimarães e de seu sobrinho...”, cit., cx. 152, doc. 56.

28 "Meu sobrinho Antônio de Abreu Martins: De idade menor te mandei ir de casa de teus pais e juntamente teu irmão, Francisco de Abreu Guimaraes, e logo que lá chegastes à cidade 
A despeito da permissividade de Ribeiro Faria, em 1781, um acontecimento se mostraria mais nebuloso: Antônio de Abreu Guimarães recebera em Lisboa 20 mil cruzados referentes a uma "partida de caixas de açúcar" e, logo depois, acreditava ter sido envenenado com um caldo de galinha em um conluio tramado por Ribeiro Faria. Abreu Guimarães começou a se sentir mal, com dores no estômago e na barriga, e passou a noite provocando vômitos, chegando a chamar um confessor, temendo morrer sem extrema-unção. Sobreviveu e deu por bem mudar-se de sua "Quinta da Portela" para outra residência no Largo do Carmo, em Lisboa.

No início de 1782, ainda debilitado, sofreu mais uma afronta: Antônio Martins e Ribeiro Faria teriam entrado em sua casa e o obrigado a dar-lhes um crédito de oito mil cruzados. Diante disso, mudou-se novamente do Largo do Carmo para os arredores do Convento de Santo Antônio dos Capuchos, onde tinha "uma casinha" havia anos e, em outubro de 1782, foi para o Convento da Cartuxa, nas proximidades de Lisboa. Os inconvenientes seguiram-se com pressões por empréstimos, chegando ao ponto de anunciarem que Antônio de Abreu Guimarães estava louco e incapaz de gerenciar os próprios negócios ${ }^{29}$.

Embora não seja possível saber ao certo quais foram as notícias que por meio de Antônio de Abreu Guimarães chegaram a seu sobrinho no além-mar, o fato é que em fevereiro de 1782, Francisco o advertia mais uma vez sobre a necessidade de fazer testamento e dispor claramente dos bens em Minas. Em maio de 1782, finalmente recebeu a tão esperada notícia de que o tio havia feito o testamento, deixando-o como testamenteiro e herdeiro. Meses depois, deu ciência do conteúdo do documento sem grande entusiasmo ${ }^{30}$. Tudo indica que naquela ocasião era pública a intenção de destinar boa parte da fortuna para fundação de obras pias.

Em mais de uma passagem da Memória, Antônio acusou o sobrinho de desviar verbas com a colaboração do irmão. Nas correspondências, as cobranças

do Rio de Janeiro, achastes por recomendação minha o falecido meu amigo doutor Francisco Prado que vos procurou e hospedou em sua casa assistindo-vos com todo o preciso, remetendo-vos para o arraial dos Carijós, onde eu era morador e sempre vos tratei e beneficiei com zelo e afeto como se fossem meus filhos". ANTT, "Memória do que tenho praticado...” cit., Hospício da Terra Santa, mç 38, cx. 10. f.1.

${ }^{29}$ ANTT, "Memória do que tenho praticado..." cit, Hospício da Terra Santa, mç 38, cx. 20. f. $4-5 \mathrm{v}$.

${ }^{30}$ Carta de 05/02/1782; Carta de 24/05/1782. Na carta de 12/11/1782, Francisco responde ao tio: "Com as mesmas recebi as duas cópias do seu novo testamento, que o vi na forma que Vossa Mercê me ordena, e não tenho que reprovar, porque sei o havia de fazer com aprovação de pessoas doutas" AHU, Minas Gerais, "Consulta do Conselho Ultramarino sobre os requerimentos de Antônio de Abreu Guimarães e de seu sobrinho...” cit., cx. 152, doc. 56. 
eram diretas, ao que Francisco sempre respondeu que o estado da Capitania das Minas Gerais não era o mesmo que o tio deixara quando partira para Lisboa. Em 21 de maio de 1786, Francisco relatou as dificuldades em cobrar devedores, com importantes figuras empenhadas: "é a figura em que estão as Minas, que Vossa Mercê julga no estado antigo" ${ }^{31}$.

Para Antônio, assim que souberam de suas intenções em vincular os bens, os sobrinhos começaram uma verdadeira cruzada na tentativa de fracassar o projeto: enquanto Antônio Martins e Ribeiro Faria conspiraram contra sua vida e sua lucidez, Francisco protelava a entrega de dividendos e ocultava informações do que acontecia nas Minas ${ }^{32}$. Quaisquer que fossem os argumentos, o fato é que em 4 de junho de 1787 um decreto régio finalmente autorizou a vinculação dos bens. Segundo sua Memória, todos planos dos sobrinhos se viram frustrados. Era o xeque-mate de Antônio de Abreu Guimarães: estava criado o vínculo da Jaguara.

\section{O vínculo da Jaguara}

Solicitado em julho de 1777 e autorizado 10 anos depois ${ }^{33}$, o vínculo da Jaguara era uma proposta irrecusável à Coroa, não obstante desde Pombal a monarquia viesse tentando controlar o volume e a natureza dos legados pios $^{34}$. Era comum que portugueses enriquecidos nas regiões coloniais desempenhassem um papel invulgar para a assistência aos pobres nos dois lados do Atlântico ${ }^{35}$. Em sua petição, Antônio fez referência à lei pombalina de 9 de setembro de 1769, sobre as restrições em vincular bens de raiz, mas argumentou que o vínculo iria converter todo o pio das fundações em utilidade pública ${ }^{36}$. Apesar do gigantismo, as propostas eram consideravelmente úteis e em acordo com

${ }^{31}$ Carta de 21/05/1786. AHU, Minas Gerais, "Consulta do Conselho Ultramarino sobre os requerimentos de Antônio de Abreu Guimarães e de seu sobrinho...” cit., cx. 152, doc. 56.

${ }^{32}$ ANTT, "Memória do que tenho praticado..." cit., Hospício da Terra Santa, mç 38, cx. 20.

${ }^{33}$ ANTT, Papeis do Brasil, Cód.6, fls. 366-367.

${ }^{34}$ Para as alterações testamentárias nas leis portuguesas, ver: Maria Antónia Lopes, "A intervenção da Coroa nas instituições de protecção social de 1750 a 1820", Revista de História das Ideias, n. 29, Coimbra (2008), p. 131-176.

${ }^{35}$ Para a relação entre emigração e caridade, ver: Isabel dos Guimarães Sá, "Misericórdias, portugueses no Brasil e brasileiros" in: Os Brasileiros de Torna Viagem, Lisboa, CNCDP, 2000, p. 117-132. Maria Marta Lobo de Araújo; Alexandra Esteves; José Abílio Coelho; Renato Franco (Coords.), Os brasileiros enquanto agentes de mudança - poder e assistência, Braga/Rio de Janeiro, CITCEM/FGV, 2013.

${ }^{36}$ ANTT, Hospício da Terra Santa, mç 38, cx. 20. 
as sensibilidades caritativas da época ${ }^{37}$. Toda a fortuna existente e a que se desejasse acrescentar posteriormente fariam parte de um fundo inalienável a ser distribuído entre as fundações. Os pareceres do procurador da Coroa e do Conselho Ultramarino saudavam a iniciativa sem objeções e o decreto régio vinculou "Jaguara, Vargem Comprida, Mocambo, Riacho da Anta, Pau de Cheiro, Forquilha, Melo, Barra do Rio Melo, com engenhos, fábricas, casas, escravos, gados e criações, além de muitas léguas de terras minerais de que se tem extraído e pode extrair muito ouro" 38.

A fortuna deveria ser aplicada em um colégio de enjeitadas e órfãs pobres; um seminário na Jaguara para enjeitados e órfãos pobres, cujos mais talentosos ganhariam bolsa de estudos na Universidade de Coimbra; um hospital para pobres, na vila do Sabará; um hospital para leprosos, em Lagoa Santa. Por fim, solicitou ainda a autorização para que se criasse um hospício, com padres da Congregação do Oratório, "por serem sujeitos hábeis e exemplares para administradores do vínculo e diretores não só dos estudos, mas também espirituais dos mesmos Seminário, Colégio e Hospitais". Chama a atenção o protagonismo dos eclesiásticos no manejo do hospital, instituição tipicamente controlada por leigos ${ }^{39}$.

O decreto de 23 de novembro de 1787 era mais preciso na partilha e gestão da fortuna, além de trazer um regimento para orientar a administração. $\mathrm{O}$ rendimento líquido seria dividido em cinco partes. Uma ficaria para o livre uso do instituidor durante sua vida e depois de sua morte; outro quinhão estava destinado ao Recolhimento das Convertidas do Rego, em Lisboa; e dos três quintos que restavam, os administradores deveriam: a) prover um subsídio anual de 800 mil réis para a Ordem Terceira do Carmo de Sabará que se

${ }^{37}$ Para as mudanças na percepção da caridade ao longo do século XVIII, ver ainda: Catherine Duprat, Pour l'amour de l'humanité - Le temps des philanthropes, Paris, Éditions Du C.T.H.S., 1993. Para o caso português, ver: Isabel dos Guimarães Sá \& Maria Antónia Lopes, História Breve das Misericórdias Portuguesas, Coimbra, Imprensa da Universidade de Coimbra, 2008. Laurinda Abreu, O poder e os pobres - as dinâmicas politicas e sociais da pobreza e da assistência em Portugal (séculos XVI-XVIII), Lisboa, Gradiva, 2014.

${ }^{38}$ ANTT, Papeis do Brasil, Cód.6, fls. 366-367.

${ }^{39}$ A Congregação do Oratório foi criada em 1668 e era uma espécie de família religiosa de padres seculares organizados por estatutos comuns, mas cujos institutos eram completamente independentes entre si. Empenhados na moralização do clero secular, os oratorianos voltaram-se também para a execução de algumas obras de misericórdia, como a visita aos presos e a hospitais; além disso, destacaram-se pelo relevante papel na educação. Seu período de maior influência data de meados do século XVIII, interrompido por embates com Pombal e retomado no período mariano, ainda que com menor vigor. Ver: Eugénio Francisco dos Santos, "Oratorianos" in: Carlos Moreira Azevedo (Dir.), Dicionário de História Religiosa de Portugal (J-P), Lisboa, Círculo dos Leitores, 2001, p. 328-334. 
responsabilizava por curar enfermos não contagiosos em casas que o instituidor deixava para o dito fim; b) financiar o seminário, colégio de órfãs, o lazareto ${ }^{40}$.

O subsídio destinado à Ordem Terceira do Carmo para socorrer pobres doentes alterava substancialmente a proposição original do instituidor, para quem parte da fortuna deveria ser direcionada à criação de um hospital, cuja administração estaria a cargo dos oratorianos. Ao contrário do que se poderia esperar, nenhuma referência à criação de uma Santa Casa de Misericórdia ${ }^{41}$. O decreto também não fazia referência à Congregação do Oratório - recomendada pelo instituidor e pelos pareceres do procurador da Fazenda e pelo Conselho Ultramarino - e tampouco concedia o monopólio da administração a padres. A junta administrativa poderia ser composta por seculares - "eclesiásticos do Hábito de São Pedro" - e por leigos.

A primeira junta administrativa seria escolhida por Antônio de Abreu Guimarães, que nomeou seu sobrinho para o cargo de presidente, com o pagamento anual de 400 mil réis. Como ordenava o decreto régio, a primeira obra pia a ser executada deveria ser o seminário destinado aos enjeitados e órfãos pobres ${ }^{42}$, as quantias devidas à Ordem Terceira e ao Recolhimento das Convertidas também poderiam ter início sem maiores delongas. Em 1787, o vínculo da Jaguara e todas as úteis obras pias pareciam ter um futuro brilhante, no entanto, Francisco sentiu-se lesado em seus interesses porque o tio havia vinculado propriedades que considerava suas.

\section{Embargos}

Quando, em 1780, Francisco solicitou o hábito da Ordem de Cristo, já havia sido capitão e, de presente, era coronel em Sabará43. Naquela altura, era um

${ }^{40}$ Ver discussões para a redação final do texto de 23/11/1787 em AHU, Minas Gerais, "Alvará de d. Maria I regulando a administração e governo dos bens vinculados por Antônio de Abreu Guimarães na comarca do Sabará, em virtude do decreto para o estabelecimento de casas de educação e hospitais, de 4 de junho 1787” (vários documentos), cx.127, doc. 24.

${ }^{41}$ Ver: Renato Franco, "O modelo luso de assistência e a dinâmica das Santas Casas de Misericórdia na América portuguesa”, Estudos Históricos, v. 27 n. 53 Rio de Janeiro (2014), p. 5-25.

${ }^{42} \mathrm{O}$ seminário chegou a funcionar regularmente atendendo meninos pobres. Ver: Thais Nivia de Lima e Fonseca, Letras, oficios e bons costumes - Civilidade, ordem e sociabilidades na América portuguesa, Belo Horizonte, Autêntica, 2009.

${ }^{43}$ AHU, Minas Gerais, "Requerimento de Francisco de Abreu Guimarães, capitão de Cavalaria Auxiliar de Dragões do distrito de Jaguara no termo de vila do Pitangui, pedindo sua conformação no exercício do referido posto", cx. 104, doc. 38. AHU, Minas Gerais, "Requerimento de Francisco de Abreu Guimarães, coronel do $1^{\circ}$. Regimento de Cavalaria Auxiliar de Vila Real do Sabará", cx. 110, doc. 41. 
homem de considerável respeito, "sempre se tratou com distinção e gravidade", "reputado entre os homens bons", "tendo muitos engenhos e lavras em que tem muita escravatura". Em seu processo de habilitação, chama a atenção o silêncio sobre quem o apoiara em sua ida para as Minas Gerais - seu tio - e a reiterada ciência dos depoentes de que Francisco possuía bens próprios ${ }^{44}$.

No entanto, essa não parecia ser a percepção dos que viviam em Minas quando o Vínculo foi anunciado. Dez anos após o decreto real, em $1^{\circ}$ de junho de 1797, Francisco subiu um pedido via Conselho Ultramarino solicitando que os processos fossem interrompidos até que todos os seus bens fossem separados do fundo inalienável; em 27 de junho do mesmo ano, enviou uma carta ao tio cobrando o pagamento de todos os serviços prestados ao longo de décadas: "é preciso que Vossa Mercê me diga quanto me dá pelo meu trabalho de 30 anos que a tanto há que aqui estou por seu respeito, sofrendo o que nunca sofreria por dinheiro algum, e sem fazer negócio algum tendo dinheiro e meios para o fazer muito avultado ${ }^{45}$. Não era mentira. $\mathrm{O}$ coronel poderia ter angariado fortunas pessoais, amparadas legalmente; por outro lado, a vinculação de todos os bens existentes nas Minas soava também como uma vingança pessoal, uma espécie de acerto de contas em que o tio, mais uma vez, ditava o destino do sobrinho. Como até 1798 Francisco não havia logrado provar que era proprietário legal de algum dos bens vinculados, foi feita uma ressalva de que se em qualquer tempo conseguisse, seu direito de posse estava assegurado ${ }^{46}$.

A resposta de Antônio, então com 84 anos, foi um requerimento, em dezembro de 1798, via Conselho Ultramarino, solicitando que se ouvissem o governador e os interessados nas Minas Gerais e expulsassem Francisco da Jaguara, porque o sobrinho estava "cheio de ambição e de orgulho", "sumamente sentido de que se aplicasse para instituições pias todas aquelas possessões, das quais ele esperava ficar senhor absoluto". O governador forneceu um interessante parecer: em primeiro lugar confirmou a posse integral de Antônio de Abreu Guimarães de todos os bens que constituíram o Vínculo, "uma das

${ }^{44}$ Outro fato curioso foi o pedido de Francisco para que as diligências fossem feitas em Lisboa, e não em Guimarães, sob a alegação de "pátria comum". ANTT, Tribunal do Santo Oficio, Conselho Geral, Habilitações, Francisco, mç. 101, doc. 1629

${ }^{45}$ Ver doc. 2 e carta de 27/06/1797. AHU, Minas Gerais, "Consulta do Conselho Ultramarino sobre os requerimentos de Antônio de Abreu Guimarães..."cit., cx. 152, doc. 56.

${ }^{46}$ AHU, Minas Gerais, "Consulta do Conselho Ultramarino sobre os requerimentos de Antônio de Abreu Guimarães...” cit., cx. 152, doc. 56. No ANTT, há duas sesmarias em nome de Francisco de Abreu Guimarães, uma de 1798, outra de 1800, porém não tive acesso a essa documentação. ANTT, Registro Geral de Mercês de D. Maria I, liv.29, f. 83; Registro Geral de Mercês de D. Maria I, liv.29, f. 126v. 
maiores possessões, se não é a principal delas, na capitania de Minas Gerais"; em segundo lugar, atestou a probidade de Francisco, tido e havido como uma figura de boa índole. O sobrinho, tal como anunciara na carta de junho de 1797, estava também empenhado em cobrar do tio todos os serviços prestados durante mais de três décadas ${ }^{47}$.

Dois anos mais tarde, em novembro de 1799, Antônio rogou à consciência de Francisco para que deixasse em paz seu projeto de vincular todos os seus bens ${ }^{48}$. No início do século XIX, Antônio de Abreu Guimarães havia sobrevivido à boa parte dos seus inimigos inclusive a Ribeiro Faria e a Antônio Martins, ambos já falecidos àquela altura. As desavenças legais entre tio e sobrinho só seriam finalmente resolvidas por meio de uma carta escrita em julho de 1801 . Poucos meses antes de sua morte, Antônio pediu perdão a Francisco pelos muitos trabalhos que lhe havia causado, além de lhe perdoar todas as dívidas, pagar-lhe todos os ordenados pelos serviços prestados no valor que Francisco arbitrasse, incentiva-lo a assumir a presidência da junta, com o pagamento de 400 mil réis anuais ${ }^{49}$.

\section{Os últimos atos}

Em fins de 1801, foi inserida a última modificação no testamento de Antônio de Abreu Guimarães. Residia no convento da Cartuxa havia quase 20 anos e pedia para que seu enterro fosse o mais simples possível "que no meu funeral não haja pompa, nem superfluidade pois detesto toda a mundana vanglória". Era irmão da Ordem Terceira de São Francisco, no Rio de Janeiro; da Ordem Terceira de Nossa Senhora do Carmo, de Lisboa; além de "algumas confrarias e irmandade da mesma cidade de Lisboa". Naquela altura, boa parte do que dispunha vinha dos $20 \%$ que lhe cabiam do rendimento líquido do vínculo da Jaguara. Com eles, beneficiou sobrinhas, freiras, instituições... Mesmo depois

${ }^{47}$ Ver, especialmente, docs 3 e 6. AHU, Minas Gerais, "Consulta do Conselho Ultramarino sobre os requerimentos de Antônio de Abreu Guimarães...” cit., cx. 152, doc. 56. (doc. 6).

${ }^{48}$ BNRJ, Manuscritos, C-1057, 12 (doc. 5), Fundo Casa dos Contos.

49 "E como me acho nos últimos fins da vida, vos peço e suplico que me perdoeis todos os incômodos e desgostos que vos tenha motivado em o decurso desses anos, e se Deus vos inspirar a resolução de ficares no emprego de Diretor enquanto viveres, desde já vos aprovo todas as contas no estado em que as tiveres ou deixares sem dependência da menor obrigação, e igualmente vós mesmo arbitrareis os ordenados que vos são devidos pela vossa administração sem a menor contenda, dispondo por meu falecimento do rendimento anual da dita quinta parte para sempre como bem vos parecer com o desconto somente dos 400 mil réis anuais e os quatro legados vitalícios enquanto não vagarem”. BNRJ, Manuscritos, C-1057, 12. 
dos desentendimentos, Francisco comprou mais fazendas que o tio em seu testamento juntou ao vínculo ${ }^{50}$.

Em uma das cláusulas, Antônio fez uma interessante reflexão sobre o sucesso conseguido nas Minas Gerais:

"Porque sempre foi minha intenção beneficiar que fosse compatível com a justiça e equidade a meu sobrinho, o coronel Francisco de Abreu Guimarães, não só pela particular afeição que sempre lhe tive e ele mereceu pelo seu bom comportamento, mas muito principalmente por ele ter há longos anos administrado a minha Casa da Jaguara com zelo, atividade e préstimo de tal sorte, que ele tem sido o principal instrumento para ela chegar ao estado em que presentemente se acha" ${ }^{\circ 1}$.

Essa cláusula específica foi anulada no testamento. De todo modo, o sobrinho aceitara a incumbência de presidir a junta, recebendo 400 mil réis e $20 \%$ do rendimento líquido do Vínculo. A primeira ata da mesa data de 9 de maio de 1802. O presidente era Francisco de Abreu Guimarães e o procurador-geral era seu sobrinho e futuro herdeiro, Francisco Lopes de Araújo. O ato inicial foi a feitura de um livro de tombo, separando tudo o que pertencia a Francisco e lembrando que "as disposições do falecido instituidor do Vínculo eram tão excessivas, que certamente nunca se poderiam preencher por não serem tão vantajosos e seguros os lucros como ele pensava"s2.

As disposições de Antônio foram abertas em Sabará, em 10 de novembro de $1807^{53}$, quando Francisco já estava morto ${ }^{54}$. O testamento do sobrinho, feito em julho de 1803 e aberto em 03 de abril de 1807, apresentava substanciais diferenças em relação ao do tio: composto por 28 verbas, o testador dispendeu uma verdadeira fortuna em obras de caridade, pulverizadas entre Minas e Portugal. Seu testamenteiro era seu sobrinho, fazendo valer, mais uma vez, a habitual estratégia familiar que caracterizava boa parte dos migrantes minhotos.

Pediu para ser enterrado com o Hábito da Ordem de Cristo, na capela de Nossa Senhora da Conceição da Jaguara, conduzido em caixão, acompanhado pela irmandade do Santíssimo Sacramento e todos os sacerdotes que estivessem

${ }^{50}$ ANTT, Feitos Findos, Registo Geral de Testamentos, Livro 349, fls.68v-75v. Ver também Biblioteca Nacional do Rio de Janeiro, Rio de Janeiro (BNRJ), Manuscritos, C-1057, 12 (doc. 1), Fundo Casa dos Contos.

${ }^{51}$ ANTT, Feitos Findos, Registo Geral de Testamentos, Livro 349, fl.75.

${ }^{52}$ APM, Casa dos Contos, cód. 1597 (1805-1835), f. 2v.

${ }^{53}$ BNRJ, Manuscritos, C-1057, 12 (doc. 1), Fundo Casa dos Contos

${ }^{54}$ APM, Secretaria de Governo (SG), Testamento de Francisco de Abreu Guimarães, cx.57, doc.78. 
na localidade; pedia um ofício de corpo presente, também com todos os sacerdotes, além de um oitavário de missas. Declarou que tinha separado todos os seus bens dos do tio; das mil missas que pediu após seu falecimento, 500 eram em intenção à sua própria alma, 50 para São Francisco de Assis, 25 para o Anjo da Guarda, 25 aplicadas para os irmãos da Ordem de Cristo, 50 pelas almas dos amigos falecidos, 25 pelas almas dos inimigos falecidos, 25 pelas almas dos falecidos com quem teve contas, 100 pelas almas de seus escravos falecidos, 100 pelas almas do Purgatório, 100 pela alma de seu tio, Antônio ${ }^{55}$.

\section{Considerações Finais}

As trajetórias dos Abreu Guimarães são reveladoras em muitos sentidos: em primeiro lugar, como já destacado, porque demonstram como a América serviu de espaço de promoção social. De origem humilde, seguramente quando atravessou pela primeira vez o Atlântico rumo ao Rio de Janeiro, Antônio de Abreu Guimarães jamais poderia sonhar que terminaria a vida como uma das maiores fortunas de sua época. Seu cabedal era fruto de grande cosmopolitismo, próprio das redes comerciais que ligavam diferentes espaços e se estendiam dos rincões de uma rústica vila no interior de Minas Gerais, passavam por Rio de Janeiro, Pernambuco, Lisboa e outros pontos que interessavam aos circuitos comerciais, extrapolando nacionalidades.

A trajetória de Antônio era também portuguesa e representativa de tantos exemplos de famílias que migraram rumo à América para tentar a sorte; prendia-se a formas de ascensão social do mundo luso: tornou-se capitão, familiar do Santo Ofício, possuía o Hábito da Ordem de Cristo, viveu e morreu como um católico, pertenceu a várias confrarias e, por fim, obstinadamente lutou para a imensa fortuna que fizera fosse destinada à caridade. No mesmo sentido, Francisco também partilhava da visão de mundo do tio: tornara-se capitão, coronel, familiar do Santo Ofício e possuía o Hábito da Ordem de Cristo; tal como o tio, era um devoto confesso, cujo testamento sinalizava a intenção de despender boa parte da fortuna em obras de caridade.

Antônio era um celibatário, cujo sucesso pessoal incentivara outros familiares também a partir; Francisco de Abreu Guimarães tinha 12 anos mais ou menos, vinha de uma família remediada, quando atravessou o Atlântico rumo às brenhas de Minas Gerais. $\mathrm{O}$ auxílio do tio garantiria o acesso a redes exclusivas de comerciantes, alimentadas por laços de amizade e reciprocidade, mas custaria ao sobrinho um preço nem sempre fácil de pagar, que o obrigaria

${ }^{55}$ APM, SG, Testamento de Francisco de Abreu Guimarães, cx.57, doc.78. 
a gerir uma fortuna cada vez maior, de maneira frequentemente subserviente. A administração da Jaguara exigiria uma dedicação incondicional, com laivos de servilidade e gratidão aliados à esperança de amealhar seu quinhão nas enormes fortunas.

A relação familiar, tipicamente patriarcal, garantiria ainda outro aspecto nebuloso, manifesto na ausência de contrato entre tio e sobrinho. Com a ausência do tio desde 1767, era plausível imaginar que Francisco esperasse se beneficiar da fortuna daquele que lhe confiara os negócios. Antônio valorizou o quanto pôde a virtual possibilidade de herança de Francisco e deveria estar ciente que a vinculação de todos os bens da Jaguara representava um fracasso de expectativas para o sobrinho. Quando em 1787 foi publicado o decreto régio, apesar de protestos Francisco não conseguiu provar a posse legal de nenhuma das fazendas. Para o capitão Antônio, o Vínculo teria garantido a preservação de sua vida, silenciando as pressões e disputas familiares pela fortuna. No entanto, anos mais tarde, assim que aceitou presidir a Junta da Jaguara, após um embate de mais de uma década em que o tio capitulara no fim da vida, o sobrinho desfez o que julgava ser injustiça, recobrando o que considerava ser seu.

Efetivamente, a vinculação de tamanhas posses para caridade parecia uma solução que ninguém abertamente ousaria questionar. Havia séculos que a ajuda aos necessitados guiava as legações pias de portugueses, cumprindo a metáfora de sociedade compassiva, pouco conflitiva e amorosa ${ }^{56}$. As escolhas de Antônio de Abreu Guimarães estavam sintonizadas, inclusive, com a sensibilidade utilitarista da segunda metade do século XVIII, centrando forças em instituições de ensino e hospitais ${ }^{57}$. No entanto, não se deve esquecer que o testamento de Francisco de Abreu Guimarães também tinha na caridade um importante esteio, valorizando formas tradicionais de auxílio, como missas, esmolas a pobres, dotes a órfãs, viúvas, afilhadas, irmandades das Minas e de Portugal, Misericórdias. Antônio, que vivia em Portugal havia anos, privilegiou a criação de instituições em Minas; Francisco, que viveu a maior parte de sua vida nas Minas, pretendeu gastar boa parte de sua fortuna em Portugal.

Aberto o testamento de Francisco, em abril de 1807, uma crise se instaurou na Jaguara e o ouvidor Antônio Luiz Pereira da Cunha emitiu um parecer sobre

${ }^{56}$ Ângela Barreto Xavier, "Amores e desamores pelos pobres: imagens, afectos e atitudes (sécs. XVI e XVII)”, Lusitania Sacra, tomo XI, (1999), p. 59-85. Maria Antónia Lopes, “Os pobres nos discursos das elites" in Pobreza, assistência e controlo social-Coimbra (1750-1850), Coimbra, Palimage Editores, 2000, p. 27-163.

${ }^{57}$ Maria Antónia Lopes e José Pedro Paiva, "Introdução" in Maria Antónia Lopes e José P. Paiva (Eds.), Portugaliae Monumenta Misericordiarum - Sob o signo da mudança: de D. José I a 1834, vol. 7, Lisboa, UMP, 2008, p. 7-36. 
a enormidade de bens legados: "Ignoro absolutamente qual seja o fundo dos bens da herança do falecido coronel Francisco de Abreu Guimarães, assim em dinheiro, como em bens (...), mas as pessoas sensatas duvidam que ele deixasse 300 mil cruzados em dinheiro"s8. Se Francisco participara do plano de matar o tio, ninguém sabe, mas parece ter se apoderado de mais fazendas do que poderia supor Antônio de Abreu Guimarães, contribuindo para inflar a imaginação dos que apostam que o sobrinho era mesmo um reles aproveitador.

Raimundo Trindade, cônego que se dedicou ao levantamento das instituições que fizeram parte da história do bispado de Mariana, recolheu um relato sobre os dois principais personagens da Jaguara ${ }^{59}$. Segundo o padre João de Santo Antônio, que no século XIX vivera em Sabará e arrematara parte da "fazenda do Melo", a riqueza de Antônio fora conseguida por meio de contrabando, razão que o fizera regressar a Portugal e consultar seu confessor, que, por sua vez, o aconselhara a pedir perdão à rainha. Assegurado o perdão régio, teria oferecido todos os seus bens à Coroa, mas como a rainha os recusara, decidiu empregar suas riquezas em obras pias. Doravante, teria decidido se tornar frade e morrera em santidade.

Ainda de acordo com o relato, apesar das boas intenções de Antônio, a Jaguara teria tido maus administradores, que gastavam em "jantares, bailes e divertimentos", desviando o dinheiro dos pobres. Francisco teria se apoderado de quatro fazendas que repartira entre seus parentes. Contra ele teria movido demanda o padre Manuel Antônio, mas d. João VI mandou pôr panos quentes porque Francisco de Abreu teria se encarregado de fazer o chafariz da Carioca, no Rio de Janeiro, e durante três anos trabalhara com escravos sem cobrar nada e "pediu a el-rei que só queria que ele mandasse pôr termo a umas demandazinhas que lhe faziam em Minas". D. João VI aceitara a proposta de Francisco, colocando-o como administrador vitalício do Vínculo, e assim ficaram pertencendo a outros as quatro fazendas: "deu Ponte Nova aos Lobos, Casa-Branca a Manuel Francisco e a João Martins, Brejo e Pau de Cheiro a duas filhas naturais".

Essa memória que misturava realidade e fantasia foi alimentada pelos públicos desentendimentos entre tio e sobrinho e certamente pela imagem de fausto que a Jaguara exibia. No início do século XIX, era exemplo visível de riquezas que poucos poderiam ombrear: a sede da Fazenda tinha um grande

\footnotetext{
${ }^{58}$ APM, SG, cx. 70, doc. 22.

${ }^{59}$ Raimundo Trindade, "Notícia sobre o vínculo do Jaguara contada pelo Padre João de Santo Antônio" in: Instituições de igrejas no Bispado de Mariana, Rio de Janeiro, SPHAN, 1945, p. 135-138.
} 
açude, onde se criavam peixes e se podia andar de escaler, à imitação do que era feito em Lagoa Santa ${ }^{60}$. A talha dos altares e as imagens que compunham a capela de Nossa Senhora da Conceição foram feitas por Aleijadinho, o maior artista mineiro de sua época ${ }^{61}$. Contudo, o espanto provocado pela riqueza que alimentaria tantas lendas formou par com o fulminante desaparecimento de uma das mais expressivas fortunas de Minas Gerais: em 1843, o vínculo da Jaguara foi extinto, pondo fim a tantas histórias de desavenças.

${ }^{60}$ Carta de 14/07/1772. AHU, Minas Gerais, "Consulta do Conselho Ultramarino sobre os requerimentos de Antônio de Abreu Guimarães...”, cx. 152, doc. 56.

${ }^{61}$ Olinto Rodrigues dos Santos Filho, "A capela da fazenda da Jaguara e o mestre Aleijadinho", Revista Imagem Brasileira, n. 2 (2003). p.67-77. 